\title{
Direct large-volume injection analysis of polycyclic aromatic hydrocarbons in water
}

\author{
Ainhoa Rubio-Clemente, ${ }^{1,2,3,{ }^{*}}$ Edwin L. Chica, ${ }^{4}$ Gustavo A. Peñuela, ${ }^{2}$
}

Edited by

Juan Carlos Salcedo-Reyes

(salcedo.juan@javeriana.edu.co)

1. Universidad Católica de Murcia UCAM, Facultad de Ciencias de la

Salud, Avenida de los Jerónimos, 135,

Guadalupe-Murcia, Spain.

2. Universidad de Antioquia UdeA,

Facultad de Ingeniería, Sede de

Investigaciones Universitarias (SIU),

Grupo de Diagnóstico y Control de la

Contaminación (GDCON),

Calle 70, No. 52-21, Medellín, Colombia.

3. Tecnológico de Antioquia-Institución

Universitaria TdeA, Facultad de

Ingeniería, Calle 78b No. 72A-220,

Medellín, Colombia.

4. Universidad de Antioquia UdeA,

Facultad de Ingeniería, Departamento de Ingeniería Mecánica, Calle 70, No. 52-21, Medellín, Colombia.

*ainhoarubioclem@gmail.com

Received: 07-10-2017

Accepted: 19-04-2018

Published on line: 05-06-2018

Citation: Rubio-Clemente A, Chica EL Gustavo, Peñuela A. Direct large-volume injection analysis of polycyclic aromatic hydrocarbons in water, Universitas Scientiarum, 23 (2): 171-189, 2018. doi: 10.11144/Javeriana.SC23-2.dlvi

\section{Funding:}

Colombian Institute of Science and Technology (COLCIENCIAS) and the Research Vice-rectory of Universidad de Antioquia.

Electronic supplementary material: N.A.

OPEN ACCESS

\begin{abstract}
Due to the health risks for both humans and living beings caused by polycyclic aromatic hydrocarbons (PAHs), the monitoring of these compounds in environmental matrices is mandatory. This work proposes an analytical method for analyzing anthracene (AN) and benzo[a]pyrene (BaP), two of the most representative PAHs, at ultra-trace concentrations in water, employing direct injection of large volumes of samples coupled with reversed-phase high-performance liquid chromatography. For this purpose, principal component analysis was used to examine the behavior of $\mathrm{AN}$ and $\mathrm{BaP}$ within the chromatographic system. Results showed that $\mathrm{AN}$ and $\mathrm{BaP}$ chromatographic behavior can be described by three models representing their identification, the quantification of $\mathrm{AN}$ and that of $\mathrm{BaP}$, respectively. The factors affecting the obtained models, such as the injection volume, column temperature, flow rate, strength of the mobile phase, and the excitation and emission wavelengths, were examined and optimized by means of design of experiments. Finally, the analytical method was validated, obtaining promising limits of detection and quantification. The developed analytical method was demonstrated to be useful for a sensitive analysis of the target analytes in relatively clean natural water matrices.
\end{abstract}

Keywords: anthracene; benzo[a]pyrene; design of experiments; matrix constituents; principal component analysis; ultra-trace level

\section{Introduction}

Aqueous resources pollution is an issue of current special concern. A number of pollutants can be found in water, including polycyclic aromatic hydrocarbons (PAHs) (Tian et al. 2012; Rubio et al., 2013; Rubio-Clemente et al. 2014a, 2015). These compounds constitute a group of organic pollutants formed of two or more fused benzene rings containing mainly carbon and hydrogen (Rubio-Clemente et al. 2014b; Dos Santos et al. 2018). PAHs are ubiquitous compounds in the environment (Alves et al. 2017; Segura 
et al. 2017). They come from anthropogenic sources, such as fossil fuel combustion, metal smelting processes and food smoking, among other human activities; and can be found in the atmosphere, soil, water and even in living beings because of their bioaccumulative properties throughout the food chain (Chizhova et al. 2013; Menezes et al. 2013; Santos et al. 2017).

The main concern related to the presence of PAHs in the environment is ascribed to their toxic potential, such as anthracene (AN), which has exhibited a high acute phototoxicity, and carcinogenic, mutagenic and teratogenic characteristics, like benzo[a]pyrene (BaP) (Rubio-Clemente et al. 2014b). In this regard, these compounds are subjected to be monitored by national and international regulations (Directive 2013; Ribeiro et al. 2015); therefore, the adoption of an analytical method aiming at their determination is required (Rubio-Clemente et al. 2017).

Due to their hydrophobicity, PAHs are poorly soluble in water, being present at ultra-trace levels in the range of $\mathrm{ng} / \mathrm{L}$ or $\mu \mathrm{g} / \mathrm{L}$; fact that limits PAH identification and quantification in aqueous matrices (Rubio-Clemente et al. 2017). Recently, several analytical techniques have been reported (Nawaz et al. 2014; Petridis et al. 2014; Ahmadvand et al. 2015; Khodaee et al. 2016). However, they use previous separation and pre-concentration procedures, being PAH analysis a tedious process. Additionally, separation and pre-concentration techniques might contaminate the sample to be analyzed and produce loses of analytes; especially when multistep procedures are performed (Buczyńska et al. 2014; Anumol et al. 2015; Boix et al. 2015). Consequently, large-volume injection techniques are proposed to be used as alternative procedures (Boix et al. 2015). Sample large-volume injection techniques can also be used with reversed-phase high-performance liquid chromatography (RP-HPLC) and gas chromatography (GC), and be combined with fluorescence detector (FLD) or diode array detector, and even with mass spectrometry, finding out accurate and repeatable results within a short period of analysis, without incurring high costs, neither the contamination of the sample nor the loss of the target analytes.

On the other hand, during the development of new analytical methods, one-factor-at-a-time techniques are commonly used. However, the evaluation of several factors influencing the chromatographic system by analyzing the effect of one single parameter at a time can be an expensive task, and valuable information about the analyzed factors can be missed (Trably et al. 2004; Hanrahan \& Lu 2006, Andrade-Eiroa et al. 2010; Rubio-Clemente et al. 2017). In this regard, multivariate statistical approaches can overcome these drawbacks by using principal component analysis (PCA) and design of experiments (DOE). PCA is a multivariate analytical tool that can be 
used to reduce a set of original variables and to extract a small number of latent factors, also called principal components (PCs), which allow the analysis of the relationships among the observed variables (Machala et al. 2001; Golobočanin et al. 2004). In turn, DOE can be used to determine the most influential factors within the considered experimental system (Ferreira et al. 2007; Dejaegher \& Vander 2009, 2011).

Under this scenario, this work is focused on analyzing $\mathrm{AN}$ and $\mathrm{BaP}$ chromatographic behavior in order to optimize the system for the simultaneous analysis of the analytes of interest at ultra-trace levels in aqueous samples by means of RP-HPLC coupled with FLD and using PCA and DOE under different experimental conditions. In addition, the validation of the optimized experimental chromatographic conditions was carried out using different natural water matrices.

\section{Materials and methods}

\section{Reagents and solutions}

Anthracene (AN, 99\%) and benzo[a]pyrene (BaP, $98 \%$ ) analytical certified standards from Dr. Ehrenstorfer (Ausgburg, Germany) and gradient-grade acetonitrile purchased from Merck (Darmstadt, Germany) were used without further purification. Deionized water with a resistivity of $18.2 \mathrm{M} \Omega$ and obtained from a Millipore purification system (Bedford, USA) was also employed.

Stock standard solutions of $\mathrm{AN}$ and $\mathrm{BaP}$ were prepared in acetonitrile at a concentration of $1000 \mathrm{mg} / \mathrm{L}$. The working solutions used during the PCA and DOE were prepared by spiking deionized water with a small aliquot of $\mathrm{AN}$ and $\mathrm{BaP}$ for obtaining a final concentration of $20 \mu \mathrm{g} / \mathrm{L}$ and $2 \mu \mathrm{g} / \mathrm{L}$, respectively.

The calibration curves were built within a range of $75-3000 \mathrm{ng} / \mathrm{L}$ for AN and of $30-3000 \mathrm{ng} / \mathrm{L}$ for $\mathrm{BaP}$, using diluted standard solutions and $10 \%$ of acetonitrile $(\mathrm{v} / \mathrm{v})$ so that the target $\mathrm{PAH}$ adsorption on the walls of the vials is prevented (Martinez et al. 2004).

\section{Analytical methods}

$\mathrm{AN}$ and $\mathrm{BaP}$ were identified and quantified in aqueous samples with an Agilent HPLC system series 1100/1200 (Palo Alto, USA) equipped with a G1322a vacuum degasser unit, a G1311a quaternary pump, a G1321a multiwavelength fluorescence detector, a G1316a column oven, and a G1329a autosampler. The 
column was a $5 \mu \mathrm{m}$ Kinetex core-shell technology C18 (150 x $4.6 \mathrm{~mm}$ i.d.) from Phenomenex (Torrance, USA). Unless otherwise mentioned, elution was carried out under isocratic conditions using a mobile phase composed of acetonitrile and deionized water $(90: 10, \mathrm{v} / \mathrm{v})$, a flow rate of $1 \mathrm{~mL} / \mathrm{min}$, a column temperature of $35^{\circ} \mathrm{C}$, a sample injection volume of $100 \mu \mathrm{L}$, an emission wavelength of $416 \mathrm{~nm}$ and excitation wavelengths of $254 \mathrm{~nm}$ from 0 to $3.20 \mathrm{~min}$ and $267 \mathrm{~nm}$ from 3.21 to $5 \mathrm{~min}$. OpenLab CDS Chemstation software (Agilent, Palo Alto, USA) was used for chromatographic data analysis.

\section{Statistical analysis}

PCA was used to examine the behavior of $\mathrm{AN}$ and $\mathrm{BaP}$ within the chromatographic system under several experimental conditions. The objective of PCA consists of building $k$ lineal combinations $(Y k)$ of the considered $(X p)$ variables containing the major variability, being $a$ the associated coefficients. The lineal combinations can be expressed as Eq. 1-3.

$$
\begin{gathered}
Y_{1}=a_{11} x_{1}+a_{12} X_{2}+\cdots+a_{1 p} X_{p} \\
Y_{2}=a_{21} x_{1}+a_{22} X_{2}+\cdots+a_{2 p} X_{p} \\
Y_{k}=a_{k 1} x_{1}+a_{k 2} X_{2}+\cdots+a_{k p} X_{p}
\end{gathered}
$$

The first PC $\left(Y_{1}\right)$ refers to the lineal combination of the response variables with the maximal variability. The second $\mathrm{PC}\left(Y_{2}\right)$ is the lineal combination with the second major variability that is not correlated with the first PC. The variability grouped by the following $\mathrm{PC}\left(Y_{k}\right)$ is decreased up to a non-statistical significant variability.

Additionally, a fractional factorial DOE was employed to find the optimal operating conditions that allow for the simultaneous identification and quantification of the target analytes.

Statgraphics Centurion XVII (Statpoint, Warrenton, USA) was used for the statistical treatment of the experimental data.

\section{Results and discussion}

\section{Chromatographic behavior using principal component analysis}

Taking into account the different factors that influence the separation of compounds in a chromatographic system for an accurate identification and quantification, the strength of the mobile phase, which was evaluated in 
terms of acetonitrile percentage, was selected to be analyzed. The injection volume is another parameter to be considered, particularly when determining compounds in the range of $\mathrm{ng} / \mathrm{L}$, as it is the case, since the injection of large volumes of samples may derive in the increase of the number of molecules and, therefore, in the increase of the detector analytical response. The excitation and emission wavelengths also play a main role in the quantification of compounds that exhibit an excitation and relaxation behavior under ultraviolet radiation, such as PAHs. Consequently, these two factors were also taken into consideration. Moreover, the flow rate of the mobile phase and the temperature of the column were demonstrated to influence the chromatographic system; that is, the determination of analytes due to the correlation between their elution and the pressure of the system. Thus, six factors affecting the chromatographic system were initially considered, and varied within different operational ranges. In Table 1 the factors and ranges used are listed. These ranges were selected according to different investigations (Bourdat-Deschamps et al. 2007; Lucio-Gutierrez et al. 2008; Andrade-Eiroa et al. 2010), the chromatographic expertise of the authors and previous experimental runs.

Among the different responses to be measured related to the identification and quantification of organic compounds, the retention time of $\mathrm{AN}$ and $\mathrm{BaP}$, as well as the resolution between these two compounds, were selected for identification purposes. Since identification is not enough, in terms of regulation accomplishment, the counts of area and height of $\mathrm{AN}$ and $\mathrm{BaP}$ were also considered for quantification purposes. In order to find out the optimal experimental conditions for $\mathrm{AN}$ and $\mathrm{BaP}$ analysis in water at ultra-trace concentrations, PCA was firstly conducted to correlate the different responses selected and, therefore, to obtain those models describing the chromatographic behavior of $\mathrm{AN}$ and $\mathrm{BaP}$. However, it is highlighted that prior to any further statistical analysis, normality of the response variables was checked. All the measured variables were verified to follow a normal distribution by using Kolmogorov-Smirnov test, with the exception of AN area and AN height. Consequently, these variables were treated and log transformations of AN area and AN height were obtained for assuring normality assumption.

Subsequently, the response variables were subjected to PCA. It was found that the first three PCs explained more than $97 \%$ of the total variability among the seven considered response variables. These results were confirmed by the scree plot represented in Fig. 1, The scree plot displays the number of principal components versus their corresponding eigenvalues. This kind of plot indicates in a graphical way the number of PCs to be retained based on the size of their eigenvalues. The ideal pattern is a steep curve that is gradually smoothed up to a straight line, as represented by the blue line in the figure. 
Table 1. Factors and levels tested for the considered responses.

\begin{tabular}{lc}
\hline \multicolumn{1}{c}{ FACTOR (UNIT) } & LEVEL \\
\hline Injection volume $(\mu \mathrm{L})$ & $50-100$ \\
\hline Strength of the mobile phase $(\%)$ & $70-90$ \\
\hline Excitation wavelength $(\mathrm{nm})$ & $230-280$ \\
\hline Emission wavelength $(\mathrm{nm})$ & $408-424$ \\
\hline Flow rate (mL/min) & $1-1.5$ \\
\hline Column temperature $\left({ }^{\circ} \mathrm{C}\right)$ & $25-35$ \\
\hline
\end{tabular}

The number of principal components suggested to be selected corresponds to those components with eigenvalues higher than 1 ; that is, the components that remain above the horizontal red line. In Table 2 , the estimated values of the coefficients for each extracted principal component are shown.

From Table 2, it can be observed that the coefficients having the main weights (weight $>0.5$ ) in PC 1 are the retention times of $\mathrm{AN}$ and $\mathrm{BaP}$, and the resolution between $\mathrm{AN}$ and $\mathrm{BaP}$; that is, all the response variables related to the elution of the target analytes. In this regard, PC 1 can be representative of the identification index of $\mathrm{AN}$ and $\mathrm{BaP}$. Concerning PC 2, the main coefficients are the log area of $\mathrm{AN}$ and the log height of $\mathrm{AN}$. In turn, for PC 3, the coefficients representing the area and height of $\mathrm{BaP}$ are the highest ones. Therefore, PC 2 and PC 3 might be indicative of the behavior of AN and $\mathrm{BaP}$, respectively, in terms of the peak area and height; that is, PC 2 and PC 3 represent the quantification index of $\mathrm{AN}$ and $\mathrm{BaP}$, respectively. PCA tool has also been used for developing retention models in liquid chromatography and standard fingerprints, among other uses (Nikitas et al. 2012; Qi et al. 2017).

\section{Optimization using design of experiments}

Once the identification and quantification of $\mathrm{AN}$ and $\mathrm{BaP}$ were described by these indeces, corresponding to PC 1, PC 2 and PC 3, the factors statistically significant for each component were examined and the experimental conditions were optimized by using DOE; particularly, a fractional factorial 
Table 2. Coefficient estimated values contained in the considered principal components.

\begin{tabular}{lccc}
\hline \multicolumn{1}{c}{ COEFFICIENT } & PC 1 & PC 2 & PC 3 \\
\hline Retention time of AN & 0.5453 & 0.0422 & 0.1432 \\
\hline Retention time of BaP & 0.5573 & 0.0511 & 0.0965 \\
\hline Area of BaP & 0.0405 & -0.3385 & 0.6593 \\
\hline $\begin{array}{l}\text { Height of BaP } \\
\text { An and BaP }\end{array}$ & -0.2635 & -0.2974 & 0.5825 \\
\hline $\begin{array}{l}\text { Log Area of AN } \\
\text { Log Height of AN }\end{array}$ & 0.5323 & 0.1019 & 0.1420 \\
\hline
\end{tabular}

design due to the high number of factors considered initially. A total of 16 runs plus 5 central points were executed within the selected operating ranges, and analysis of variance (ANOVA) test was performed for each chromatographic index. For a confidence interval of $95 \%$, it was observed that the block effect was not significant for the chromatographic system under the tested experimental conditions. Concerning PC 1, representing the identification index of $\mathrm{AN}$ and $\mathrm{BaP}$, it was evidenced to be influenced negatively by the flow rate and the strength, in terms of acetonitrile content of the mobile phase. This means that as the flow rate is increased, the analytes elute faster and the resolution is, subsequently, decreased. This inversely proportional linear relationship between resolution and flow rate was also observed by Andrade-Eiroa et al. (2010) while optimizing the separation of the pairs dibenzo[a,h]anthracene-benzo[g, h, i]perylene and benzo[g, h, i] perylene-indeno[1, 2, 3-cd]pyrene. Similar reasoning can be withdrawn when considering the percentage of organic solvent in the mobile phase. An increase of the mobile phase strength leads to $\mathrm{AN}$ and $\mathrm{BaP}$ are eluted more rapidly, decreasing their retention times by the stationary phase of the chromatographic column, which results in a decrease of resolution between these two organic compounds. From these two factors, the flow rate was found to exert a higher influence in the identification index of both pollutants, since it has a coefficient associated of -2.1767 in comparison with the coefficient linked to the acetonitrile percentage $(-0.1774)$ of the mobile phase. 


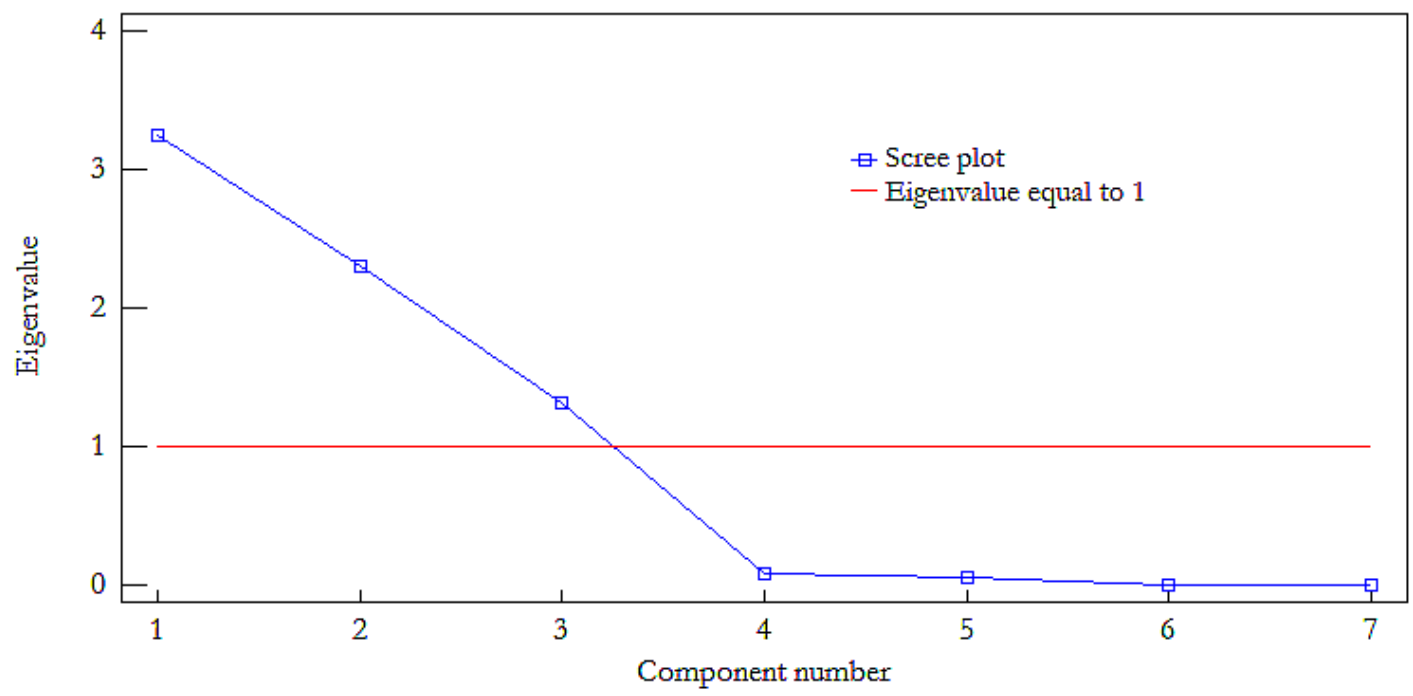

Figure 1. Scree plot of the considered responses. Operating conditions: [anthracene] $0=20 \mu \mathrm{g} / \mathrm{L}$; [benzo[a]pyrene] $0=2 \mu \mathrm{g} / \mathrm{L}$; injection volume $=50-100 \mu \mathrm{L}$; strength of the mobile phase $=70-90 \%$; excitation wavelength $=$ 230-280 nm; emission wavelength $=408-424 \mathrm{~nm}$; flow rate $=1-1.5 \mathrm{~mL} / \mathrm{min}$; column temperature $=25-35^{\circ} \mathrm{C}$.

With respect to PC 2, representing AN quantification index, the excitation wavelength was observed to develop a major role in $\mathrm{AN}$ area and height with a weight of -0.0542 . This fact indicates that a decrease of the excitation wavelength results in an increase of the index describing AN quantification and, therefore, an increase of the log area and of the log height of AN. Thus, $\mathrm{AN}$ area is increased as well as $\mathrm{AN}$ height, improving $\mathrm{AN}$ signal detected by the FLD.

Finally, concerning PC 3, it was found that it is statistically affected by the injection volume by a weight of 0.0286 . Thus, when the injection volume is increased, the amount of $\mathrm{BaP}$ molecules eluting is correspondingly increased with the subsequent augmentation of the area and height of $\mathrm{BaP}$ chromatographic peak. Additionally, for a significant level equal to 0.05, the flow rate and the excitation wavelength exerted a negative $(-2.1898)$ and positive (0.0190) influence, respectively. On the one hand, an increase of the flow rate of the mobile phase leads to a decrease of the area of $\mathrm{BaP}$ peak. This can be explained from the fastest elution of the analyte molecules, reducing $\mathrm{BaP}$ band and, therefore, decreasing the dimensions of $\mathrm{BaP}$ peak. On the other hand, an increase of the excitation wavelength results in an increase of the area and height of $\mathrm{BaP}$. It must be noted that, despite the 
non-statistically significance of the excitation wavelength for $\alpha=0.05$, it was considered in the $\mathrm{BaP}$ quantification index because its p-value was close to 0.05 ( $p$-value $=0.0772$ ).

In Fig. 2, the described magnitudes and signs of the selected factors, both the statistically and non-statistically significant ones, for the three PCs are represented through the main effect plots.

The models built describing the three chromatographic indeces representing the chromatographic behavior of $\mathrm{AN}$ and $\mathrm{BaP}$ under the experimental conditions tested with p-values lower than 0.05 , corresponding to 0.0000 , 0.0000 and 0.0085 , respectively, are described by Eq. 4-6.

$$
\begin{aligned}
& I_{i}=16.9144-2.1767 * F R-0.1774 * S \\
& I_{i i}=13.8225-0.0542 * E W \\
& I_{i i}=-4.2625-2.1898 * F R+0.0286 * I V+0.0190 * E W
\end{aligned}
$$

where $I_{i}$ is the AN and BaP identification index, $I_{i i}$ is the AN quantification index and $I_{i i i}$ is the BaP quantification index. In turn, $F R, S, E W$ and $I V$ represent the flow rate, strength of the mobile phase, excitation wavelength and the injection volume of the sample, respectively.

By optimizing all the principal components obtained simultaneously using multicriteria decision approach, the optimal chromatographic conditions with a desirability of $83.52 \%$ were $1.0 \mathrm{ml} / \mathrm{min}, 90 \%, 100 \mu \mathrm{L}, 230 \mathrm{~nm}, 409 \mathrm{~nm}$ and $25^{\circ} \mathrm{C}$ for the flow rate, acetonitrile content of the mobile phase, injection volume, excitation and emission wavelengths and the column temperature, respectively. However, it is worldwide known that the absorption and fluorescence emission capacities of a substance depend on the substance itself. Additionally, absorption and fluorescence properties of the particularly tested compounds do not follow a linear relationship with the wavelengths used, since their absorption molar coefficients and absorption spectra vary with the single excitation wavelength (Rubio-Clemente et al. 2017). For example, in the case of AN, the absorption coefficient at $254 \mathrm{~nm}$ is $\log \varepsilon_{254}=4.9$ in ethanol. For BaP, it has a value of $\log \varepsilon_{254}=4.6$ in ethanol (Zsila et al. 2006; Jones, 1947). BaP absorption spectrum is characterized by several bands of varied intensity; a first one in the range between 245 and $305 \mathrm{~nm}$, higher than $254 \mathrm{~nm}$; and a second one from 320 to $410 \mathrm{~nm}$ (Thomas \& Burgess, 2007). Moreover, AN absorption spectrum has a distinguished band around $254 \mathrm{~nm}$ (Thomas \& Burgess, 2007). In this regard, the optimization procedure used in this work is limited when the studied system is influenced by the quadratic effects of the considered factors, as it is the case for these parameters. 
(a)

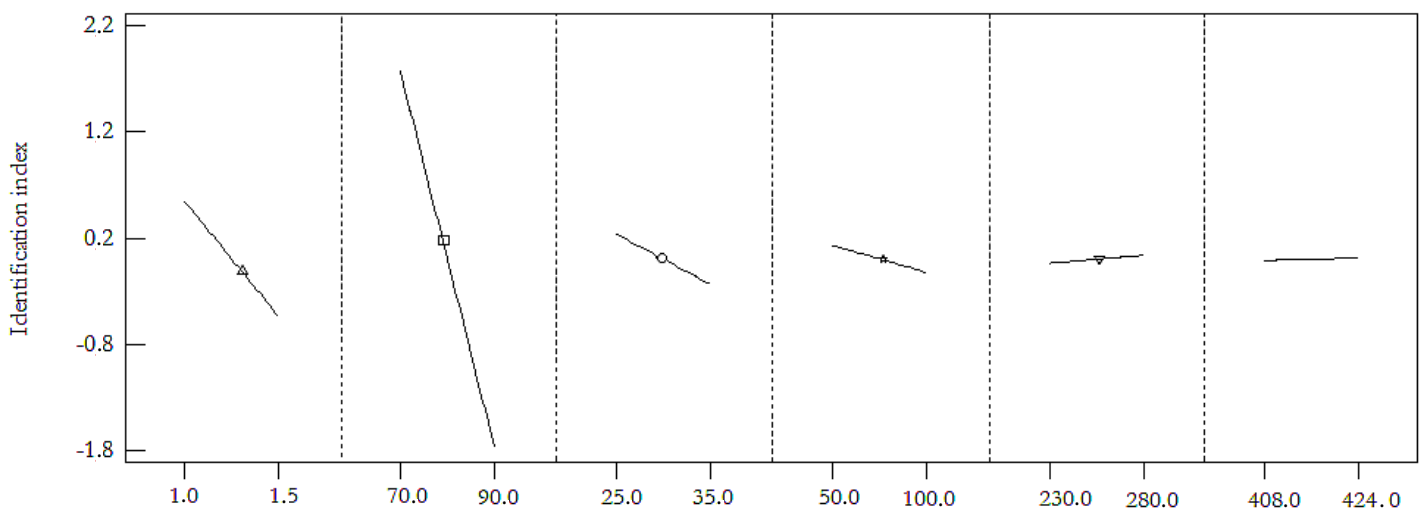

(b)

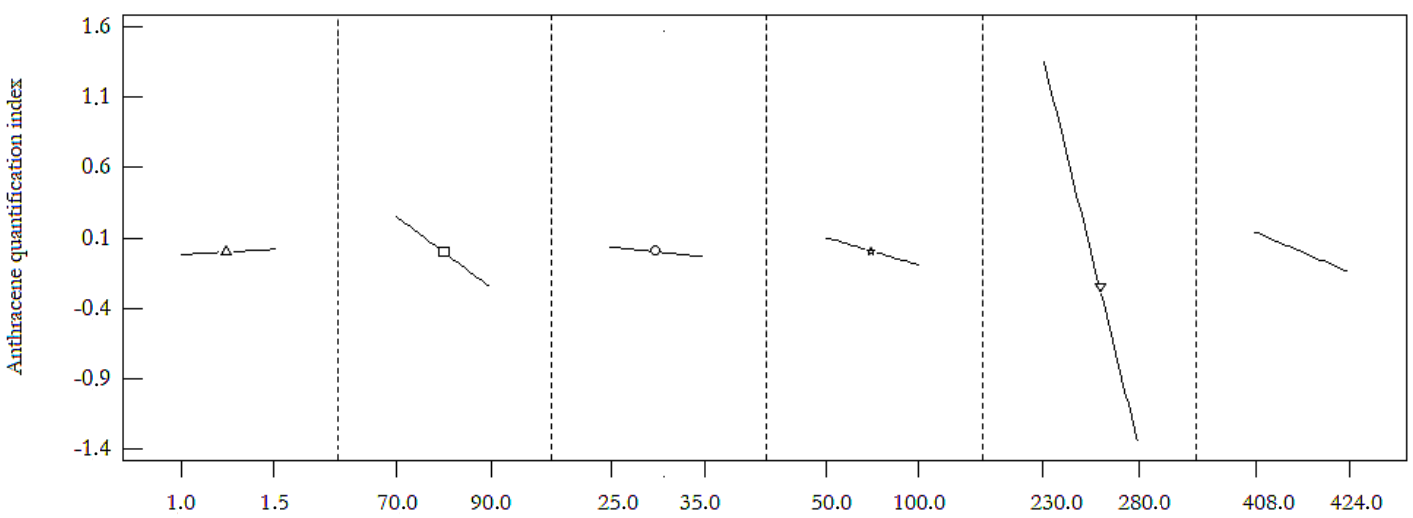

(c)

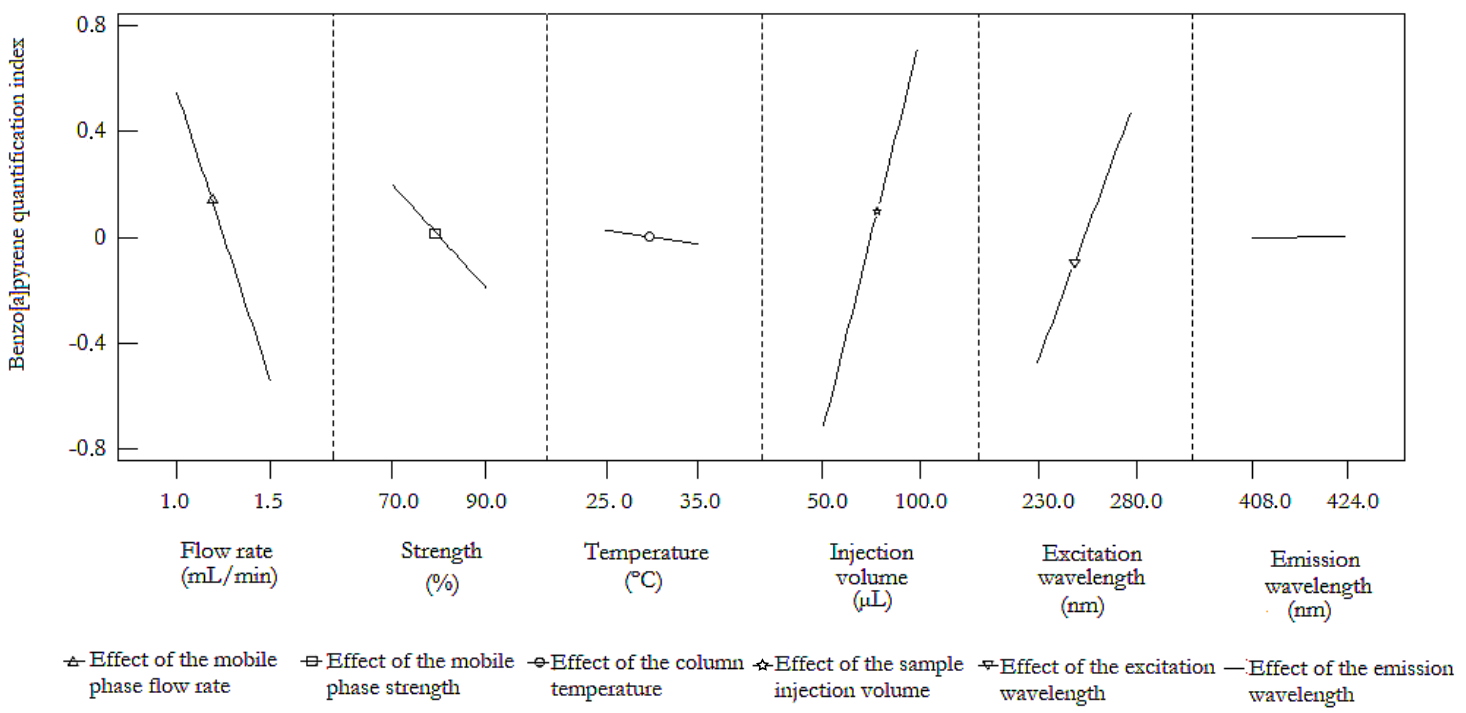

Figure 2. Main effect plots for the identification i ndex (a), anthracene quantification index (b) and benzo[a]pyrene quantification index (c). Operating conditions: [anthracene] $0=20 \mu \mathrm{g} / \mathrm{L}$; [benzo[a]pyrene] $0=2 \mu \mathrm{g} / \mathrm{L}$; injection volume $=50-100 \mu \mathrm{L}$; strength of the mobile phase $=70-90 \%$; excitation wavelength $=230-280 \mathrm{~nm}$; emission wavelength $=408-424 \mathrm{~nm}$; flow rate $=$ $1-1.5 \mathrm{~mL} / \mathrm{min}$; column temperature $=25-35^{\circ} \mathrm{C}$. 
Therefore, a minacious study was subsequently performed to find out the excitation and emission optimal wavelengths of $\mathrm{AN}$ and $\mathrm{BaP}$. It was found that $416 \mathrm{~nm}$ was the optimal emission wavelength within the selected initial range for both of the examined analytes. The excitation wavelength was fixed at $254 \mathrm{~nm}$ and $267 \mathrm{~nm}$ during $\mathrm{AN}$ and $\mathrm{BaP}$ elution time, respectively.

On the other hand, taking into account that the column temperature was not statistically significant for the models built and considering that the analysis time can be reduced by augmenting the temperature of the column oven, reducing also the pressures in the system and improving the column efficiency, as reported by Andrade-Eiroa et al. (2010), the optimal column temperature was kept at $35^{\circ} \mathrm{C}$.

\section{Validation}

Under the optimized conditions, the proposed analytical method was validated. Good linearity values and low limits of quantification and detection of 75 and $5.54 \mathrm{ng} / \mathrm{L}$ for $\mathrm{AN}$, and 30 and $4.26 \mathrm{ng} / \mathrm{L}$ for $\mathrm{BaP}$ were obtained. Additionally, intraday and interday precisions lower than 2 and $11 \%$, respectively, were found for the high, medium and low levels tested. Accuracy was also verified and relative standard deviations (RSD) lower than $10 \%$ were evidenced. Furthermore, the analysis of $\mathrm{AN}$ and $\mathrm{BaP}$ in different matrices of real natural water gave satisfactory recoveries ( $\mathrm{RSD}<13 \%$ ).

\section{Conclusions}

The results of the present study indicated that the chromatographic behavior of the selected PAHs under the experimental conditions tested may be explained by PCA using three indeces describing the elution of $\mathrm{AN}$ and $\mathrm{BaP}$, the peak shape of $\mathrm{AN}$ and that of $\mathrm{BaP}$, representing the former one and the latter ones the identification and the quantification of the target compounds, respectively. It was demonstrated that the identification index of the target compounds under the experimental domain studied here was defined by the flow rate and the strength of the mobile phase. Concerning the AN quantification index, the excitation wavelength was found to develop a main role. Finally, the $\mathrm{BaP}$ quantification index, as expected, was also influenced by the excitation wavelength; however, the injection volume and the flow rate were observed to exert also a main function.

The optimal operating conditions found using DOE that maximizing the indices referred above were $1 \mathrm{~mL} / \mathrm{min}, 90 \%, 35^{\circ} \mathrm{C}, 100 \mu \mathrm{L}$, and $416 \mathrm{~nm}$ for the flow rate, acetonitrile content of the mobile phase, column temperature, injection volume and the emission wavelength, respectively. The optimal excitation wavelengths were $254 \mathrm{~nm}$ and $267 \mathrm{~nm}$ for $\mathrm{AN}$ and $\mathrm{BaP}$. The developed and validated method showed to be suitable for the identification 
and quantification of $\mathrm{AN}$ and $\mathrm{BaP}$ at ultra-trace levels in relatively clean natural water by direct injection in only $5 \mathrm{~min}$ of analysis.

\section{Acknowledgements}

This work was supported by the Colombian Institute of Science and Technology (COLCIENCIAS) and the Research Vice-rectory of Universidad de Antioquia.

\section{Conflicts of interest}

The authors state that their sole interest in the results of this research is scientific.

\section{References}

Ahmadvand M, Sereshti H, Parastar H. Chemometric-based determination of polycyclic aromatic hydrocarbons in aqueous samples using ultrasound-assisted emulsification microextration combined to gas chromatography-mass spectrometry, Journal of Chromatography A, 1413: 117-126, 2015.

doi: 10.1016/j.chroma.2015.08.026

Alves CA, Vicente AM, Custódio D, Cerqueira M, Nunes T, Pio C, Lucarelli F, Calzolai G, Nava S, Diapouli E, Eleftheriadis K, Querol X, Musa BA. Polycyclic aromatic hydrocarbons and their derivatives (nitro-PAHs, oxygenated PAHs, and azaarenes) in PM 2.5 from Southern European cities, Science of the Total Environment, 595: 494-504, 2017.

doi: $10.1016 /$ j.scitotenv.2017.03.256

Andrade-Eiroa A, Dievart P, Dagaut P. Improved optimization of polycyclic aromatic hydrocarbons (PAHs) mixtures resolution in reversed-phase high-performance liquid chromatography by using factorial design and response surface methodology, Talanta, 81(1-2): 265-274, 2010.

doi: 10.1016/j.talanta.2009.11.068

Anumol T, Wu S, Marques M, Daniels KD, Snyder SA. Rapid direct injection LC-MS/MS method for analysis of prioritized indicator compounds in wastewater effluent, Environmental Science: Water Research \& Technology, 2015(1): 632-643, 2015.

doi: $10.1039 /$ c5ew00080g

Boix C, Ibáñez M, SanchoJV, Rambla J, Aranda JL, Ballester S, Hernández F. Fast determination of 40 drugs in water using large volume direct injection liquid chromatography-tandem mass spectrometry, Talanta, 131: 719-727, 2015.

doi: 10.1016/j.talanta.2014.08.005 
Bourdat-Deschamps M, Daudin JJ, Barriuso E. An experimental design approach to optimise the determination of polycyclic aromatic hydrocarbons from rainfall water using stir bar sorptive extraction and high performance liquid chromatography-fluorescence detection, Journal of Chromatography A, 1167(2): 143-153, 2007.

doi: 10.1016/j.chroma.2007.08.025

Buczyńska AJ, Geypens B, van Grieken R, de Wael K. Large-volume injection combined with gas chromatography/isotope ratio mass spectrometry for the analysis of polycyclic aromatic hydrocarbons, Rapid Communications in Mass Spectrometry, 28: 200-208, 2014.

doi: $10.1002 / \mathrm{rcm} .6769$

Chizhova T, Hayakawa K, Tishchenko P, Nakase H, Koudryashova Y. Distribution of PAHs in the northwestern part of the Japan Sea, DeepSea Research Part II: Tropical Studies in Oceanography, 86-87: 19-24, 2013.

doi: 10.1016/j.dsr2.2012.07.042

Dejaegher B, Vander Y. The use of experimental design in separation science, Acta Chromatographica, 21: 161-201, 2009.

doi: 10.1556/achrom.21.2009.2.1

Dejaegher B, Vander Y. Experimental designs and their recent advances in set-up, data interpretation and analytical applications, Journal of Pharmaceutical and Biomedical Analysis, 56(2): 141-158, 2011.

doi: 10.1016/j.jpba.2011.04.023

Directive 2013. Directive 2013/39/EU of the European parliament and of the council of 12 August 2013 amending directives 2000/60/ EC and 2008/105/EC as regards priority substances in the field of water policy, Official Journal of the European Union L, 226: 1-17.

Retrieved from: https://eur-lex.europa.eu/legal-content/EN/ ALL/?uri=CELEX\%3A32013L0039

Dos Santos IF, Ferreira SLC, Domínguez C, Bayona JM. Analytical strategies for determining the sources and ecotoxicological risk of PAHs in river sediment, Microchemical Journal, 137: 90-97, 2018.

doi: 10.1016/j.microc.2017.09.025

Ferreira SLC, Bruns RE, da Silva EGP, dos Santos WLN, Quintella CM, David JM, de Andrade JB, Breitkreitz MC, Jardim ICSF, Neto BB. Statistical designs and response surface techniques for the optimization of chromatographic systems, Journal of Chromatography A, 1158: 2-14, 2007.

doi: 10.1016/j.chroma.2007.03.051 
Golobočanin DD, Škrbić BD, Miljević NR. Principal component analysis for soil contamination with PAHs, Chemometrics and Intelligent Laboratory Systems, 72(2): 219-223, 2004.

doi: 10.1016/j.chemolab.2004.01.017

Hanrahan G, Lu K. Application of factorial and response surface methodology in modern experimental design and optimization, Critical Reviews in Analytical Chemistry, 36(3-4): 141-151, 2006.

doi: $10.1080 / 10408340600969478$

Jones RN. The ultraviolet absorption spectra of anthracene derivatives, Chemical Reviews, 41(2): 353-371, 1947.

doi: $10.1021 / \operatorname{cr} 60129 \mathrm{a} 013$

Khodaee N, Mehdinia A, Esfandiarnejad R, Jabbari A. Ultra trace analysis of PAHs by designing simple injection of large amounts of analytes through the sample reconcentration on SPME fiber after magnetic solid phase extraction, Talanta, 147: 59-62, 2016.

doi: $10.1016 /$ j.talanta.2015.09.025

Lucio-Gutiérrez JR, Salazar-Cavazos ML, Waksman NH, Castro-Ríos R. Solid-phase microextraction followed by high-performance liquid chromatography with fluorimetric and UV detection for the determination of polycyclic aromatic hydrocarbons in water, Analytical Letters, 41(1):119-136, 2008.

doi: $10.1080 / 00032710701746758$

Machala M, Dusek L, Hilscherova K, Kubinova R, Jurajda P, Neca J, Ulrich R, Gelnar M, Studnickovà Z, Holoubek, I. Determination and multivariate statistical analysis of biochemical responses to environmental contaminants in feral freshwater fish Leuciscus cephalus L, Environmental Toxicology and Chemistry, 20(5): 1141-1148, 2001.

doi: $10.1002 /$ etc. 5620200528

Martinez E, Gros M, Lacorte S, Barceló D. Simplified procedures for the analysis of polycyclic aromatic hydrocarbons in water, sediments and mussels, Journal of Chromatography A, 1047(2): 181-188, 2004.

doi: 10.1016/s0021-9673(04)01100-8

Menezes HC, Paiva MJ, Santos RR, Sousa LP, Resende SF, Saturnino JA, Paulo BP, Cardeal ZL. A sensitive GC/MS method using cold fiber SPME to determine polycyclic aromatic hydrocarbons in spring water, Microchemical Journal, 110: 209-214, 2013.

doi: 10.1016/j.microc.2013.03.010 
Nawaz MS, Ferdousi FK, Rahman MA, Alam AM. Reversed phase SPE and GC-MS study of polycyclic aromatic hydrocarbons in water samples from the river Buriganga, Bangladesh, International Scholarly Research Notices, 2014: 1-9, 2014.

doi: 10.1155/2014/234092

Nikitas P, Pappa-Louisi A, Tsoumachides S, Jouyban A. A principal component analysis approach for developing retention models in liquid chromatography, Journal of Chromatography A, 1251: 134-140, 2012.

doi: 10.1016/j.chroma.2012.06.049

Petridis NP, Sakkas VA, Albanis TA. Chemometric optimization of dispersive suspended microextraction followed by gas chromatographymass spectrometry for the determination of polycyclic aromatic hydrocarbons in natural water, Journal of Chromatography A, 1355: 46-52, 2014.

doi: 10.1016/j.chroma.2014.06.019

Qi X, Zhu L, Wang C, Zhang H, Wang L, Qian H. Development of standard fingerprints of naked oats using chromatography combined with principal component analysis and cluster analysis, Journal of Cereal Science, 74: 224-230, 2017.

doi: $10.1016 /$ j.jcs.2017.02.009

Ribeiro AR, Nunes OC, Pereira MFR, Silva AMT. An overview on the advanced oxidation processes applied for the treatment of water pollutants defined in the recently launched Directive 2013/39/EU, Environment International, 75: 35-51, 2015.

doi: 10.1016/j.envint.2014.10.027

Rubio A, Chica EL, Peñuela GA. Wastewater treatment processes for the removal of emerging organic pollutants, Ambiente \& Agua-An Interdisciplinary Journal of Applied Science, 8(3): 93-103, 2013.

doi: 10.4136/ambi-agua.1176 645

Rubio-Clemente A, Chica E, Peñuela GA. Application of Fenton process for treating petrochemical wastewater, Ingeniería y Competitividad, 16(2): 211-223, 2014a.

Rubio-Clemente A, Chica E, Peñuela GA. Petrochemical wastewater treatment by photo-Fenton process, Water, Air, \& Soil Pollution, 226: $1-18,2015$.

doi: 10.1007/s11270-015-2321-x 
Rubio-Clemente A, Chica E, Peñuela G. Rapid determination of anthracene and benzo(a)pyrene by high-performance liquid chromatography with fluorescence detection, Analytical Letters, 50(8): 1229-1247, 2017.

doi: 10.1080/00032719.2016.1225304

Rubio-Clemente A, Torres-Palma RA, Peñuela GA. Removal of polycyclic aromatic hydrocarbons in aqueous environment by chemical treatments: A review, Science of the Total Environment, 478: 201-225, 2014b.

doi: 10.1016/j.scitotenv.2013.12.126

Santos LO, dos Anjos JP, Ferreira SL, de Andrade JB. Simultaneous determination of PAHS, nitro-PAHS and quinones in surface and groundwater samples using SDME/GC-MS, Microchemical Journal, 133: 431-440, 2017.

doi: 10.1016/j.microc.2017.04.012

Segura A, Hernández-Sánchez V, Marqués S, Molina L. Insights in the regulation of the degradation of PAHs in Novosphingobium sp. HR1a and utilization of this regulatory system as a tool for the detection of PAHs, Science of the Total Environment, 590-591: 381-393, 2017.

doi: 10.1016/j.scitotenv.2017.02.180

Thomas O, Burgess C. UV-visible spectrophotometry of water and wastewater (Vol. 27). Elsevier Science, The Netherlands, 2007.

Tian W, Bai J, Liu K, Sun H, Zhao Y. Occurrence and removal of polycyclic aromatic hydrocarbons in the wastewater treatment process, Ecotoxicology and Environmental Safety, 82: 1-7, 2012.

doi: 10.1016/j.ecoenv.2012.04.020

Trably E, Delgènes N, Patureau D, Delgènes JP. Statistical tools for the optimization of a highly reproducible method for the analysis of polycyclic aromatic hydrocarbons in sludge samples, International Journal of Environmental Analytical Chemistry, 84(13): 995-1008, 2004.

doi: 10.1080/03067310412331298412

Zsila F, Matsunaga H, Bikádi Z, Haginaka J. Multiple ligand-binding properties of the lipocalin member chicken $\alpha 1$-acid glycoprotein studied by circular dichroism and electronic absorption spectroscopy: The essential role of the conserved tryptophan residue, Biochimica et Biophysica Acta (BBA)-General Subjects, 1760(8): 1248-1273, 2006.

doi: 10.1016/j.bbagen.2006.04.006 


\section{Análisis de inyección directa en gran volumen de hidrocarburos aromáticos policíclicos en agua}

Resumen. Los hidrocarburos aromáticos policíclicos (HAPs) causan problemas en la salud de los seres humanos y seres vivos, por lo que se requiere un monitoreo de estos compuestos en matrices ambientales. Este trabajo propone un método analítico para analizar el antraceno (AN) y el benzopireno (BAP), los hidrocarburos más representativos en concentraciones de ultra trazas en el agua, empleando inyección directa en grandes volúmenes en muestras acopladas a la fase inversa con cromatografía líquida de alto rendimiento. Por tal razón, se utilizó el análisis de componentes principales para examinar el comportamiento de AN y BAP en el sistema cromatográfico. Los resultados mostraron que el comportamiento cromatográfico de AN y BAP podría describirse por medio de tres modelos que representan su identificación, la cuantificación de AN y de BAP, respectivamente. Se examinaron los factores que afectan a los modelos obtenidos, como el volumen de inyección, la temperatura de la columna, la tasa de flujo, la fuerza de la fase móvil, y las longitudes de las ondas de excitación y emisión, y se optimizaron mediante el diseño de experimentos. Finalmente, se validó el método analítico, obteniendo límites de detección y cuantificación. Se demostró que el método analítico desarrollado fue útil para el análisis sensible de los analitos en matrices de agua natural relativamente limpia.

Palabras clave: antraceno; benzopireno; diseño de experimentos; componentes matriciales; análisis de componentes principales; ultra trazas. 


\section{Análise de injeçáo direta de grande volume de hidrocarbonos aromáticos policíclicos em água}

Resumo. Devido aos riscos para a saúde tanto para humanos como para os seres vivos em geral causados pelos hidrocarbonos aromáticos policíclicos (HAPs), o monitoramento de estes compostos em matrizes ambientais é prioritário. Este trabalho propõem um método analítico

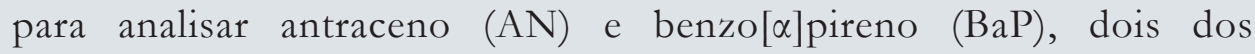
hidrocarbonos mais representativos, em concentrações de ultra traços em água, empregando injeções diretas de grandes volumes de amostra acoplada a cromatografia líquida de alta eficiência em fase reversa. Usando Análises por Componentes Principais e desenho experimental, foram avaliados os efeitos de diversos fatores que afetam o sistema cromatográfico, tais como o volume de injeção, a temperatura da coluna, fluxo, forca da fase móvel e comprimentos de onda de excitação e emissão. Os resultados demonstraram que o comportamento cromatográfico de $\mathrm{AN}$ e $\mathrm{BaP}$ pode ser descrito por meio de três que representam sua identificação, quantificação de $\mathrm{AN}$ e de $\mathrm{BaP}$, respectivamente. Os resultados mostraram que o comportamento cromatográfico de NA e BAP poderia ser descrito por meio de três modelos que representam sua identificação, a quantificação de NA e de BAP, respectivamente. Examinaram-se os fatores que afetam aos modelos obtidos, como o volume de injeção, a temperatura da coluna, a taxa de fluxo, a forca da fase móvel, e as longitudes das ondas de excitação e emissão, e se otimizaram mediante o desenho experimental. Finalmente, se validou o m todo analítico, obtendo os limites de detecção e quantificação. O método analítico desenvolvido demonstrou ser útil para uma análise sensível para os compostos de interesse em matrizes de água natural relativamente limpas.

Palavras-chave: antraceno; benzopireno; desenho experimental; componentes de matriz; análise de componentes principais; ultra traços. 


\section{Ainhoa Rubio-Clemente}

She is an Environmental Engineer by University of Salamanca. She has a MSc. and she is a junior researcher. She has research experiences in the field of water pollution decontamination and drinking water production using conventional and advanced treatment processes. Additionally, she has been involved in developing several analytical methods.

\section{Edwin L. Chica}

He is a Mechanical Engineer by University of Antioquia. Currently he is a MSc. PhD. associate professor and researcher at University of Antioquia, heading the Research Group 'Energía Alternativa'. He has research experiences in the field of renewable energy production and water decontamination and purification using conventional and advanced treatment processes, regarding design, scaling and performance purposes.

\section{Gustavo A. Peñuela}

He is a Chemist by the National University. He is the director of the Research Group 'Diagnóstico y Control de la Contaminación' (GDCON) at University of Antioquia. He has large experience in the field of water, soil and air pollution. Additionally, he has conducted a number of researches in developing analytical methods for several purposes. 